\title{
Specifics of Interrelations among Emotional, Personal and Intellectual Characteristics in Preschool Children: Data Mining
}

\author{
Elena Slavutskaya \\ Yakovlev Chuvash State Pedagogical University, \\ Cheboksary, Russia
}

Evgeni Nikolaev

Chuvash State University,

Cheboksary, Russia

\author{
Natalya Vostretsova \\ Yakovlev Chuvash State Pedagogical University, \\ Cheboksary, Russia
}

\author{
Anna Zakharova \\ Chuvash State University, \\ Cheboksary, Russia \\ e-mail zaharova_an@mail.ru
}

\author{
Svetlana Petunova \\ Chuvash State University, \\ Cheboksary, Russia
}

\begin{abstract}
The relationships of intellectual signs with selfesteem and emotional characteristics of 5-7-year old preschoolers are studied. For this purpose, traditional methods of diagnostics were used: "Method of Express Diagnostics of Intellectual Abilities (MEDIA)", "Ladder", "House. Tree. Man", "Choose the right person". The research was based on preschool institutions in Moscow and Cheboksary. Correlation, factor analysis, and artificial neural networks were used to process psychological testing data and evaluate the relationships between different psychological indicators. It is shown that even with a small sample of respondents, such a comprehensive data mining allows detecting new features in the conditions when the results of testing of preschool children have integer scales with a limited range of values. Some gender features in intellectual indicators and their interrelations with emotional and personal characteristics are revealed. On the basis of quantitative data analysis, the most significant subtests and symptom complexes from the used methods were identified. The results obtained allow demonstrating the possibilities and advantages of using artificial neural networks for processing psychodiagnostic data. The tools used are available to practical psychologists because they are part of most modern software packages for statistical data processing.
\end{abstract}

Keywords — psychodiagnostics, data mining, preschoolers, intellectual indicators, emotions, self-esteem, artificial neural networks.

\section{INTRODUCTION}

The study of the relationship between emotional, personal, behavioral characteristics and intelligence is one of the most important tasks for analyzing the children's mental development. Numerous studies in this direction concern mainly adults and schoolchildren, as well as the study of factors of psychological readiness of children for school [1, 2].
For children, starting from the age of 8-10 years, enough developed, and one can choose methods of psychodiagnostics with the same scaling of numerical data. However, for preschoolers, widespread psychological tests usually have different scales with a limited number of integer indicators. Such data for assessing the relationships between different psychological characteristics will not always allow adequate use of correlation or factor analysis. Therefore, a comprehensive data mining of preschool children psychodiagnostics, in particular, the apparatus of artificial neural networks is proposed.

Artificial neural networks (ANN) [3, 4], based on cognitive principles [5] and being one of the most important components of modern methods of artificial intelligence and data mining [6-9], can be used in different areas of psychology $[10,11]$. For statistical processing of psychodiagnostic data, the ANN apparatus has not yet been widely used. Russian psychologists use traditional statistical methods for this purpose: correlation, factor, regression analysis, etc. [12]. At the same time, most software products (including Russian ones) that are widely used for data analysis (such packages as "STATISTICA", "Deductor", etc.) make it possible to use ANN for these purposes.

Most of the research on gender features of intelligence, emotional sphere and personal characteristics (in particular, children's self - esteem [13]) presented in the Russian psychological literature is devoted to the problem of determining these features by cultural and social context, including in preschool age $[14,15]$. According To L. I. Bozhovich, the correct formation of self-esteem is one of the most important factors in the development of a child's personality. Stable self-esteem of a preschooler depends on intellectual indicators, emotional characteristics and is formed under the influence of evaluation by others (adults and 
percentage is much higher for boys $(78 \%$ of children with IIS+IS). It is interesting to analyze the influence of intelligence and signs of emotional distress on self-esteem. In addition, there is a question of identifying the most important intellectual indicators for this age and their relationship with the rest (from other tests) of data. Test results have different digital scales. Using an ANN with a simple architecture, it is possible to analyze the relationships between the source psychodiagnostic data on a relatively small sample [11].

To assess the relationships and grouping of psycho diagnostic data, correlation and factor analysis as traditional methods were used, which, when dividing respondents by gender, allows assessing the gender differences of the psychological characteristics links [14]. Varimax normalized method for the factor load matrix rotation was used. $\lambda$ is the factors eigenvalues, $S$ - percentage contribution of the factor to the total variance.

Preliminary data processing revealed the significant gender differences (see table 1). Table 2 shows the correlation coefficients between intellectual indicators according to the "MEDIA" test for boys and girls separately. For a sample of 27-29 children (preschoolers from Moscow), the 5\% significance level for the two-side criterion corresponds to a Pearson correlation coefficient of approximately 0.29 . From the data in table 2 it follows that for boys all intellectual indicators are related to each other with a level of significance sometimes in hundredths of a percent. For girls, we can consider that the results differ fundamentally: all intellectual indicators for them show such statistically significant links only with the QQR sign. And the level of correlation between intellectual indicators is generally lower for girls.

TABLE II. CORRELATION COEFFICIENTS OF INTELLECTUAL INDICATORS FOR BOYS AND GIRLS.

\begin{tabular}{|c|c|c|c|c|c|c|c|c|c|}
\hline \multicolumn{9}{|c|}{ BOYS } & \multicolumn{5}{c|}{ GIRLS } \\
\hline MEDIA & $\boldsymbol{V}$ & $\boldsymbol{Q Q R}$ & $\boldsymbol{L T}$ & $\boldsymbol{M A}$ & $\boldsymbol{M E D I A}$ & $\boldsymbol{V}$ & $\boldsymbol{Q Q R}$ & $\boldsymbol{L T}$ & $\boldsymbol{M A}$ \\
\hline V & 1.00 & 0.77 & 0.60 & 0.65 & $\mathrm{~V}$ & 1.00 & 0.44 & 0.28 & 0.26 \\
\hline QQR & 0.77 & 1.00 & 0.56 & 0.61 & $\mathrm{QQR}$ & 0.44 & 1.00 & 0.57 & 0.59 \\
\hline LT & 0.60 & 0.56 & 1.00 & 0.47 & $\mathrm{LT}$ & 0.28 & 0.57 & 1.00 & 0.34 \\
\hline MA & 0.65 & 0.61 & 0.47 & 1.00 & MA & 0.26 & 0.59 & 0.34 & 1.00 \\
\hline
\end{tabular}

Tables 3 and 4 show the factor analysis results for the relationship between emotional distress signs and self-esteem for children of different sexes. According to the Kaiser criterion, 5 factors are identified whose eigenvalues are greater than 1 .

Comparison of the data presented in tables 3 and 4 and the results of correlation analysis carried out separately for boys and girls in Moscow and Cheboksary allows drawing the following general conclusions:

1. Anxiety on the $\mathrm{CP}$ test is not related to anxiety on the HTM test. This is a general pattern that manifests itself for girls and boys from different Kindergartens (Moscow and Cheboksary).

2. Boys' self-esteem is not associated with the rest of the test data (factor 5), while girls' self-esteem is associated with signs of emotional distress (the first factor with the self-esteem. This is considered the norm for children of this age that ensures full mental development [16]. However, this 
maximum contribution to the overall variance). This is also a general rule, which is confirmed by the results of correlation analysis of data for children from different Kindergartens.
3. The relationships between signs of emotional distress from the results of the HTM test differ significantly for children of different sexes.

TABLE III. FACTOR ANALYSIS RESULTS (BOYS)

\begin{tabular}{|c|c|c|c|c|c|}
\hline \multirow{2}{*}{ Signs } & \multicolumn{5}{|c|}{ Factor Loadings } \\
\hline & Factor 1 & Factor 2 & Factor 3 & Factor 4 & Factor 5 \\
\hline Insecurity (HTM1) & 0.228 & 0.746 & 0.106 & -0.383 & -0.199 \\
\hline \begin{tabular}{|l|} 
Anxiety \\
(HTM2)
\end{tabular} & 0.0535 & 0.0126 & 0.854 & 0.102 & -0.201 \\
\hline Self-distrust (HTM3) & -0.241 & 0.091 & -0.717 & 0.004 & -0.346 \\
\hline Feelings of inferiority (HTM4) & 0.815 & 0.222 & 0.140 & 0.079 & 0.101 \\
\hline $\begin{array}{l}\text { Hostility } \\
\text { (HTM5) }\end{array}$ & 0.659 & 0.175 & 0.191 & 0.549 & 0.047 \\
\hline $\begin{array}{l}\text { Conflict } \\
\text { (HTM6) }\end{array}$ & 0.793 & -0.344 & 0.068 & 0.002 & 0.089 \\
\hline $\begin{array}{l}\text { Communication Difficulties } \\
\text { (HTM7) }\end{array}$ & 0.073 & 0.093 & -0.235 & -0.864 & -0.172 \\
\hline Depression (HTM8) & -0.115 & 0.906 & -0.121 & 0.010 & 0.089 \\
\hline Choose the right person $(\mathrm{CP})$ & -0.349 & 0.205 & 0.178 & -0.784 & 0.069 \\
\hline $\begin{array}{l}\text { Self-esteem } \\
(\mathrm{L})\end{array}$ & 0.132 & -0.013 & -0.001 & 0.097 & 0.938 \\
\hline $\begin{array}{l}\text { Expl.Var } \\
(\lambda) \\
\end{array}$ & 1.999 & 1.634 & 1.417 & 1.835 & 1.143 \\
\hline $\begin{array}{l}\text { Prp.Totl } \\
(\mathrm{S}, \%)\end{array}$ & 20 & 16 & 14 & 18 & 11 \\
\hline
\end{tabular}

TABLE IV. FACTOR ANALYSIS RESULTS (GIRLS)

\begin{tabular}{|c|c|c|c|c|c|}
\hline \multirow[t]{2}{*}{ Signs } & \multicolumn{5}{|c|}{ Factor Loadings } \\
\hline & Factor 1 & Factor 2 & Factor 3 & Factor 4 & Factor 5 \\
\hline Insecurity (HTM1) & 0.850 & 0.289 & 0.144 & 0.141 & -0.074 \\
\hline Anxiety (HTM2) & 0.120 & -0.623 & 0.004 & 0.003 & 0.607 \\
\hline Self-distrust (HTM3) & 0.078 & 0.915 & 0.071 & 0.034 & 0.022 \\
\hline Feelings of inferiority (HTM4) & -0.026 & -0.043 & -0.001 & -0.119 & -0.941 \\
\hline Hostility (HTM5) & 0.504 & 0.473 & -0.345 & -0.322 & 0.316 \\
\hline Conflict (HTM6) & 0.053 & 0.025 & 0.059 & 0.934 & 0.076 \\
\hline $\begin{array}{l}\text { Communication Difficulties } \\
\text { (HTM7) }\end{array}$ & 0.352 & 0.050 & -0.731 & 0.056 & -0.131 \\
\hline Depression (HTM8) & 0.242 & 0.077 & 0.758 & 0.316 & -0.016 \\
\hline Choose the right person $(\mathrm{CP})$ & 0.096 & -0.086 & -0.689 & 0.531 & 0.268 \\
\hline Self-esteem (L) & 0.788 & -0.307 & -0.261 & 0.013 & 0.179 \\
\hline $\operatorname{Expl.Var}(\lambda)$ & 1.813 & 1.645 & 1.801 & 1.396 & 1.487 \\
\hline Prp.Totl (S,\%) & 18 & 16 & 18 & 14 & 15 \\
\hline
\end{tabular}

The factor analysis results of emotional distress and selfesteem for senior preschool age boys and girls allow stating the following:

- the first factor for the boys showed a close connection between the following symptoms (signs of emotional distress): feelings of inferiority, hostility and conflict; for the girls, insecurity and self-esteem are directly related to each other;

- the second factor for the boys showed the relationship of the following symptoms (signs of emotional distress): insecurity and depression; for the girls - the feedback of anxiety and self-distrust;

- the third factor for the boys showed the relationship of anxiety and self-distrust; for the girls - the relationship of depression and emerging difficulties in communication;

- the fourth factor for the boys revealed a link between difficulties in communication and anxiety in social interaction (CP - test); for the girls, a high rate of conflict is allocated as a separate factor; 
- in the fifth factor, boys have a high self-esteem index, which does not depend on any symptom complexes (signs of emotional distress); girls have a direct relationship of anxiety and feelings of inferiority.

Boys' self-esteem is not related to emotional indicators. For the girls, self-esteem is directly related to feelings of insecurity. Girls' low self-esteem is caused by experiences that occur due to the deterioration of relationships with loved ones. For the boys, this event does not affect self-esteem. This is because the relationship with the reference social group is more important for girls.

An example of the used ANN is shown in figure 1.

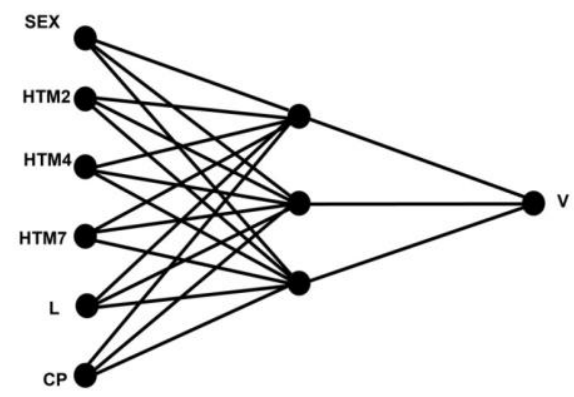

Fig. 1. Example of the ANN structure

Here, the ANN structure has already been optimized based on the results of preliminary data analysis. Only the most significant signs, in the context of connection with intellectual indicators, are submitted to the neural network input. The output is successively fed four intellectual signs using the "MEDIA" method. That is, the V is replaced with by QQR, the ANN is trained again, and so on. The results of training the ANN with different intellectual indicators at its output are shown in table 5 .

TABLE V. ANN TRAINING RESULTS

\begin{tabular}{|c|c|c|c|}
\hline $\begin{array}{c}\text { Output } \\
\text { Sign }\end{array}$ & $\begin{array}{c}\text { Maximum error - } \\
\sigma_{M}\end{array}$ & Standard error - $\sigma_{s}$ & $\begin{array}{c}\text { Links } \\
\text { recognition - } \\
R\end{array}$ \\
\hline $\mathrm{V}$ & $1,45 \times 10^{-1}$ & $1,62 \times 10^{-2}$ & $96,43 \%$ \\
\hline $\mathrm{QQR}$ & $1,96 \times 10^{-1}$ & $2,04 \times 10^{-2}$ & $91,07 \%$ \\
\hline $\mathrm{LT}$ & $4,00 \times 10^{-1}$ & $2,99 \times 10^{-2}$ & $91,07 \%$ \\
\hline MA & $3,78 \times 10^{-1}$ & $2,69 \times 10^{-2}$ & $87,50 \%$ \\
\hline
\end{tabular}

The comparative analysis of the ANN training results allow us to conclude that vocabulary is the most significant intellectual indicator based on the results of using the "MEDIA" test - it has the most structured links with children's self-esteem and emotional characteristics, even taking into account their gender differences (the child's gender was taken into account in the ANN structure, see Fig.1). This psychological feature corresponds to the maximum percentage of recognized links (computational paths) and the minimum errors in ANN training (see table 5). One can quantify the quality of ANN training and, consequently, the relationship between its input and output data by using the error distribution histogram (see figure 2). Here, the horizontal axis is the relative learning error, and the vertical axis is the number of respondents (their percentage) for whose neural network training corresponds to this error.

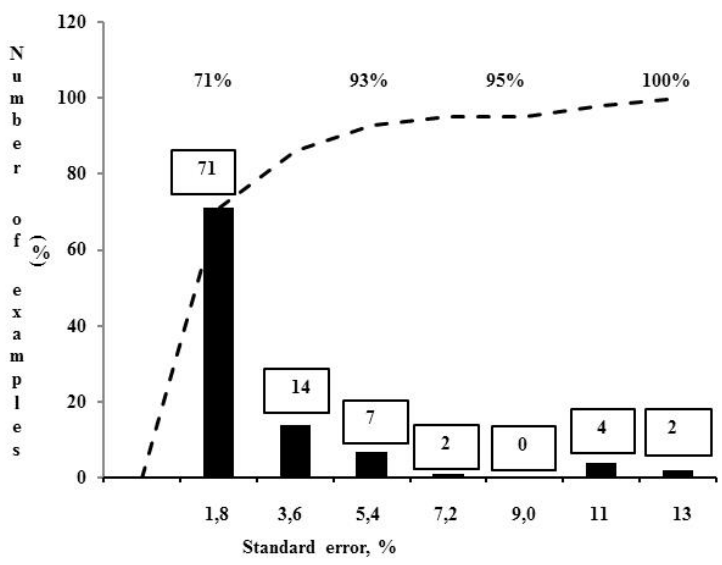

Fig. 2. Histogram of error distribution during ANN training. The solid curve is the sum with accumulation

According to the histogram data, for 53 children (95\%) out of a total sample of 56 preschoolers, the error in estimating the relationship between input data and the output sign $\mathrm{V}$ does not exceed $8 \%$. Appropriate estimates are difficult to obtain using correlation or factor analysis due to differences in the numerical test scales. In addition, the ANN allows one to select three children from the total sample whose results are "knocked out" of the specified error. This gives the psychologist the opportunity to individually check the test results, carry out additional psychodiagnostics, etc.

\section{CONCLUSION}

Thus, the results of the preschoolers' emotional, personal characteristics and intelligence study allow us to draw the following conclusions:

1. In the self-esteem of senior preschoolers, there are gender differences, which are manifested in the features of the relationship between self-esteem and the emotional sphere of boys and girls.

2. To form an adequate self-esteem in senior preschoolers based on their personal characteristics of self perception, it is important for the boys to reduce the manifestation of aggression and hostility, for the girls-to correct self-esteem is necessary taking into account with a subjective sense of insecurity.

3. The ANN, as a tool for psychological research, allows one make assessments based on gender differences and analyze the data of each preschooler - how much they 
[7] S. Samarasinghe, Neural Networks for Applied Sciences and Engineering: From Fundamentals to Complex Pattern Recognition. 1-st edition. Boca Raton: Auerbach Publications, 2006, 570 p.

correspond to it)

The results presented in this article allow us to assert that the vocabulary of preschool children, as one of the intellectual indicators by the "MEDIA" test, has structured links with anxiety (by the tests HTM and CP), self-esteem (L), as well as with communication difficulties and feelings of inferiority (HTM4, HTM7). This does not contradict the known data. The study of the relationship between the emotional sphere and intellectual indicators is one of the most important problems of psychology [18-19]. For these purposes, the ANN can be used adequately and effectively. In most modern Russian and foreign software products, all calculations and graphical representation of results are performed automatically, which allows psychologists to use this tool, not necessarily having special mathematical skills.

In conclusion, we note that the use of ANN as a data analysis tool has significant prospects for widespread use in psychological research. The very process of ANN training and building ANN models allows for system analysis of psychodiagnostic data on a relatively small sample (50-100 people). The use of a neural network as a tool based on fuzzy logic allows us to evaluate intra-system connections regardless of the numerical dimension of the source data. This can be especially important when testing preschool children, for whom tests often have scales of a very limited range. It is also important that, in contrast to traditional methods of statistical evaluation, its allow you to get estimates of the relationships of psychological characteristics not only on the average for the sample, but also selectively for each respondent.

\section{References}

[1] N.I. Gutkina, Psychological readiness for school: a textbook, St. Petersburg: Piter, 2007, 208 p

[2] T.I. Shulga, "The emotional-volitional component of psychological readiness for teaching schoolchildren", Bulletin of MGOU. Series: Psychological Sciences, vol. 1, pp. 60-66, 2012.

[3] V.V. Kruglov, V.V. Borisov, Neural networks. Theory and practice. Moscow: Goryachaya liniya Telekom Publ., 2001, 287 p

[4] S. Haykin, Neural networks: A comprehensive Foundation. New York: Prentice Hall, 1999, p. 768.

[5] D. Hebb, Organization of behavior. New York: Science Edition, 1961. p. 416-426.

[6] I.H. Witten, E. Frank, M.A. Hall, M. Kaufmann, Data Mining: Practical Machine Learning Tools and Techniques, 3rd ed. Amsterdam: Elsevier, 2011, 629 p
[8] J. Schmidhuber, "Deep Learning in Neural Networks: An Overview", Neural Networks, vol. 61, pp. 85-117, 2014. doi: 10.1016/j.neunet.2014.09.003.

[9] H. Su, G. Li , D. Yu, F. Seide, "Error back propagation for sequence training of context-dependent deep networks for conversational speech transcription", In Proceedings of International Conference on Acoustics Speech and Signal Processing (ICASSP), pp. 6664 - 6668, 2013, May [2013 IEEE International Conference on Acoustics, Speech and Signal Processing, p. 8790, 2013] DOI:10.1109/ICASSP.2013.6638951

[10] N.S. Reznichenko, S.N. Shilov, V.V. Abdulkin, "Neuron Network Approach to the Solution of the Medical-Psychological Problems and in Diagnosis Process of Persons with Disabilities (Literature Review)", Journal of Siberian Federal University. Humanities \& Social Sciences, vol. 9(6), pp.1256-1264, 2013.

[11] E.V. Slavutskaya, L. A. Slavutskii, "Preteen Age: The Analysis of the Society. Integration. Education, Proceedings of the Scientific Conference, vol. 5, pp. 455-464, 2018, may [Society. Integration. Education, p. 483, 2018] URL: http://dx.doi.org/10.17770/sie2018vol1.3348

[12] A.V. Vorobiev, "A Survey of the Application of Mathematical Methods in Psychological Research", Psychological research: electron. scientific journal, vol. 2 (10), 2010

[13] V.S. Cherniavskaya, A. F. Buslova, "Gender differences in the selfesteem of preschoolers", Scientific and Methodological Electronic Journal "Concept", vol. 7 (July), pp. 36-40, 2015. URL: http://ekoncept.ru/2015/15230.htm

[14] E. Slavutskaya, E. Nikolaev, G. Ivanova, I. Yusupov, "Gender Characteristics Of Junior Adolesents' Personal Traits", The European Proceedings of Social \& Behavioural Sciences, vol. XLIII, pp. 522-527, 2018, may. [ECCE 2018 VII International Conference Early Childhood Care and Education, p. 694, 2018] URL: https://dx.doi.org/10.15405/epsbs.2018.07.69

[15] E.I. Lebedeva, N.N. Talanova, E.A. Sergienko, "The role of psychometric intelligence in preschool children understanding of the social world, Psikhologicheskie Issledovaniya, vol. 5, No 26, p. 3, 2012 http://psystudy.ru.

[16] L.I. Bozhovich, Personality and its formation in childhood, St Petersburg: Piter, 2008, 400 p.

[17] T. V. Bendas, Gender Psychology: A Training Manual, St. Petersburg: Piter, 2007, $431 \mathrm{p}$

[18] T.A. Ratanova, "Age-related features of the differentiation and integration of cognitive structures in schoolchildren", Psychology issue, vol. 2, pp. 34-41, 2014.

[19] E.I. Shcheblanova, "Interrelation of cognitive abilities and personality characteristics of intellectually gifted schoolchildren", Psychology issues, vol.1, pp. 13-23, 2013. Multilevel Psycho-Diagnostic Data Based on Neural Network Models". 